were developed in so grave a case, the dulness being so illmarked and vocal fremitus and zocal resonance practically normal, the breath sounds, too, were quite superficial and the temperature below $100^{\circ}$ after the ninth day of disease until the eighteenth after aspiration. The chief signs for active treatment were a frequent pulse, which became irregular, and dyspncea. The urine was normal and there was no cardiac murmur. No portion of rib was excised on either side.

St. Andrews.

\section{A CASE OF DIFFUSE PAPILIOMATOUS DEGENERATION OF THE NASAL MUCOUS MEMBRANE.}

By G. HUNTER MACKENZIE, M.D. EdiN.,

SURGEON FOR THROAT AND NOSE DISEASES TO THE EYE, EAR, AND THROAT INFIRMARY, EDINBURGH.

NASAL papillomata are of rare occurrence. The few cases hitherto recorded have generally been instances of single, less frequently of multiple, growths, and their histological characters have usually been rather of the fibrous than of the true papillomatous character. Hence the term "papillomatous fibroma" which it has been proposed to apply to them. In several instances they appear to have been simple hypertrophies of the nasal mucous membrane. Ordinary mucous polypi, it may be mentioned, occasionally develop papillomata on their surface, especially if they have been exposed to external irritation. 'The following case seems worthy of being recorded on account of the many points of interest which it possesses.

A man aged thirty years came to me on April 2nd, 1896, complaining of partial nasal obstruction and stuffiness. In May, 1887, he appeared to have had both nostrils electro-cauterised on account of thickening of the mucous membrane. There was no history of syphilis, but he was somewhat alcoholic. The mucous membrane

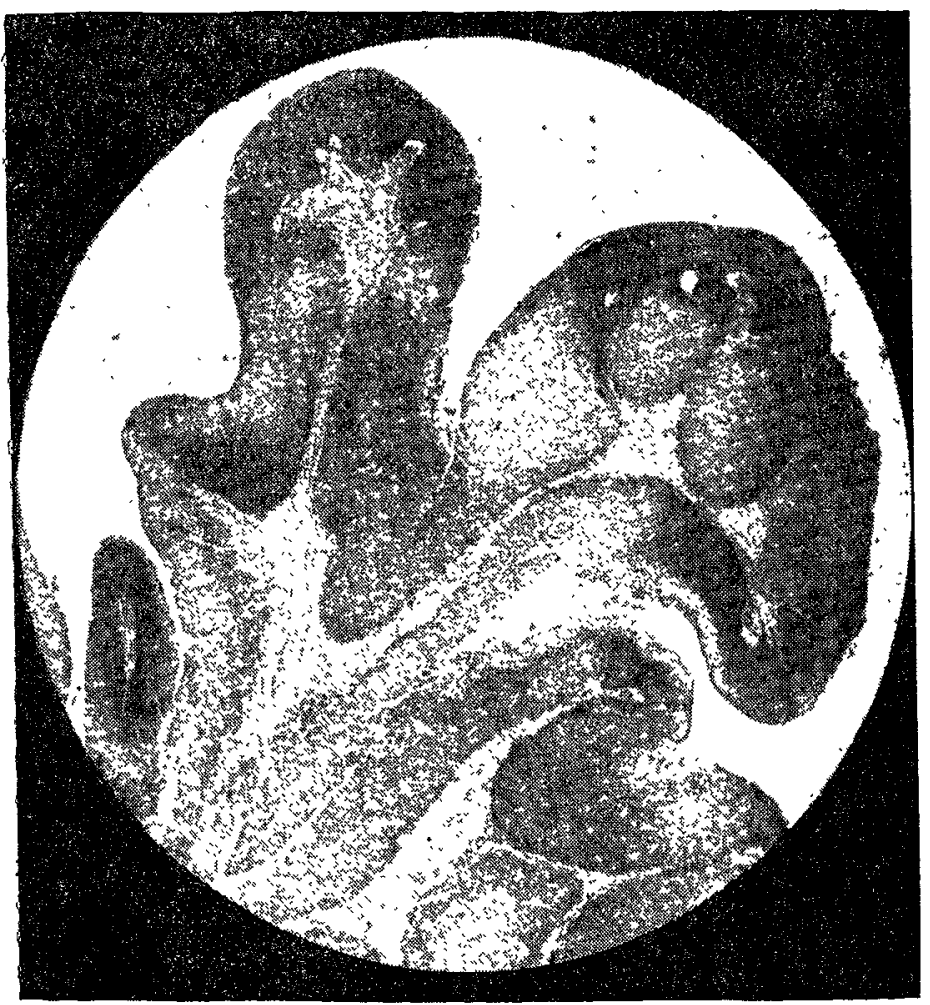

Papilloma of nose. Photo-micograph $\times 20 \mathrm{D}$.

in both nostrils was studded throughout by numerous sessile growths varying in size from a pin's head to almost a grain of rice, the size of the great majority of them being about intermediate between these two extremes. They were most abundant on and about the upper regions (roof, outer wall, and septum), but many were located on and about the inferior areas of the nose. Both nostrils appeared to be equally affected. Several of the larger growths were removed with the cold snare, but the greater number could be detached only by means of the nasal curette. Four months afterwards there was no recurrence. The growths were examined microscopically by Dr. R. F. C. Leith, who submitted the following report: "Microscopical examination shows the undoubted papillomatous character of the growths. The central core of fibrous tissue varies in thickness, but is mostly thin. It consists of young vascular fibrous tissue. The epithelial covering is of considerabie thickness and while the lower cells are columnar and elongated, the rest are typical flattened squamous, such as are present in an ordinary papilloma of the skin. Many of the cells show prickle processes. The outmost cells are somewhat flattened, but there is no cornification such as the stratum corneum of the skin presents. The conversion here seen of the columnar glandular epithelial covering of the nasal mucous membrane into cells exactly similar to those of the Malpighian layer of ordinary stratified squamous epithelium is very interesting" (vide illustration).

Edinburgh.

\section{NOTES ON THE TREATMENT OF HEART DISEASE BY MECHANICALLY- RESISTED MOVEMENTS.}

BY GEORGE HERSCHELL, M.D. LOND.,

PHYSICIAN TO THE NATIONAT, HOSPITAL FOR DISEASES OF THE HEART, ETC., SOHO-SQUARE.

Putring aside as a point yet to be settled whether the baths in use at Nauheim and their imitations in this country have any real curative power in disease of the heart, the evidence in favour of the practical utility of the resisted movements in selected cases is overwhelming. My experience, however, leads me to believe that we can obtain better and more constant results by substituting a mechanical resistance to the movements, for that offered by a nurse. My reasons are the following. 1. A mechanial resistance is more scientific insomuch as it admits of being exactly measured. 2. It is more constant as it does away with the personal equation of the operator. It is quite impossible even after long practice for a nurse to be certain of offering the same amount of resistance to movements on each occasion, for, as a matter of fact, she does not ever know how much force she is really exerting. 3. With the aid of mechanical resistance we can improve very much upon the Nauheim movements, which I venture to assert are by no means the best which can be devised for the purpose. 4. The exercises which can be used when the movements are mechanically resisted are more rapid in their action than those used in the Nauheim treatment. As an example I have convinced myself by actual observation and experiment that five minutes' use of a certain simple movement will temporarily increase the circumference of the arm of a healthy muscular man by one inch. This it can only have accomplished by withdrawing blood from the general circulation into the tissues of the limb.

To produce a mechanical resistance we may make use of either a pulley weight apparatus or one in which the effect is produced by tension of rubber cords. As a result of my experiments I have decided that the rubber cord presents many advantages. My reasons are mainly the following: 1. In a machine in which the resistance is produced by a weight the force to be exerted by the operator is the same at all points in the range of movement. Moreover, it is actually necessary to exert the most power at the commencement of any given stroke or movement in order to overcome the inertia of the machine and start the weight from its point of rest. Now this is just what we do not want. I am informed by professional gymnasts that it is a fact well recognised by them that a muscle is not able without strain to exert its full force until it has got well under weigh-so to speak-and for this reason they prefer apparatus worked by an indiarubber cord in which the power exerted by the machine slightly increases continually up to the end of the movement. 2. A pulley weight apparatus is more difficult to apply to patients in the recumbent position. On the other hand a machine consisting of a rubber cord passing round pulleys can be attached in many different ways to the bed or the adjacent wall. 3 . The difference in price. A pulley weight apparatus costs several pounds; the 